http://garmian.edu.krd

https://doi.org/10.24271/garmian.162

\title{
Toxicity Effect of Ethanolic Leaf Extracts of Mentha arvensis and Nerium oleander on Larva of Ectomyelois ceratoniae Zeller (Lepidoptera: Pyralidae)
}

\author{
Rawezh Hakeem ${ }^{1}$, Redwan Kawa ${ }^{2}$, Hana Hashim ${ }^{3}$ \\ 1 Department of Biology, Harran University, Graduate school of natural and applied science, \\ Sanliurfa, Turkey. rawezhhakim@gmail.com \\ 2 Department of Biology, Salahaddin University, Irbil, Iraq, redwan_kawa@yahoo.com \\ 3 Assistant Lecturer, Department of Biology, Salahaddin University, Irbil, Iraq, \\ hana.mohammad@su.edu.krd
}

\begin{abstract}
The ethanolic extract of two plants Mentha arvensis (Lamiaceae) and Nerium oleander (Apocynaceae) were tested for direct toxicity action on last phase larvae of Ectomeylois ceratoniae (Lepidoptera: Pyralidae), one of the most serious pests on pomegranates and other trees. Three sets of Concentration $2.5 \%, 5 \%$ and $7.5 \%$ were tested. Percent mortality was recorded at intervals of time for each plant extract. Data analysis was made by using Complete Randomized Design (CRD). The results showed that mortality effect varies according to extract type, concentration and time period .The time $12 \mathrm{~h}$ showed higher insecticidal effect with the tested plants, Strong toxicity effect was observed at concentration $7.5 \%$. The $\mathrm{LT}^{\mathbf{5 0}}$ values were 1.10, 1.05 and 0.30 for Mentha arvensis and 1.75, 1.48 and 0.90 for Nerium oleander.
\end{abstract}

Keywords: Mentha arvensis, Nerium oleander, Ectomeylois ceratoniae, insecticides.

\section{INTRODUCTION}

Nowadays control of insect pests is primarily dependent upon synthetic insecticides such as organophosphates, carbamates, pyrethroids and neonicotinoids. Controlling pests is not an easy task although synthetic chemicals are apparently available for use. Although synthetic organic chemicals have been used as an 
effective means of insect pest control for many years, their repeated use for decades has disrupted biological control by natural enemies and led to outbreak of insect species, undesirable effects on non-target organisms. These insecticides are often associated with residues that are dangerous for the consumer and the environment and at certain doses are toxic to humans and other animals, and some insecticides are suspected to be carcinogens $[1,2]$. The number of insect species with confirmed resistance to synthetic pesticides has continued to rise, apart from the risks associated with the use of these chemicals $[3,4]$. Moreover, it has been estimated that about 2.5 million tonnes of pesticides are used on crops each year and the world wide damage caused by pesticides reaches million dollars annually [5]. Furthermore, for the possibility of producing quality foodstuffs, it is necessary, among other things, to reduce the risks associated with excessive application of high pesticide doses in primary agricultural production. The current trend is the search for and use of alternative methods to manage pests, which, in the economic context, are effective without presenting the risks associated with the use of conventional pesticides. Plants have acquired effective defense mechanisms that ensure their survival under adverse environmental factors. In addition to morphological mechanisms, plants have also developed chemical defense mechanisms towards organisms such as insects that affect biochemical and physiological functions [7]. The use of botanical pesticides to protect plants from pests is very promising because of several distinct advantages. Pesticidal plants are generally much safer than conventionally used synthetic pesticides. Pesticidal plants have been in nature as its component for millions of years without any ill or adverse effect on the ecosystem. In addition, plant-based pesticides are renewable in nature and cheaper. Also, some plants have more than one chemical as an active principle responsible for their biological properties. Phytochemicals degrade rapidly, are unlikely to persist in soil and leach into groundwater, often have a reduced impact on non-target populations and are important components of 
integrated pest management systems used by organic farmers. Many botanicals may be applied to food crops shortly before harvest without leaving excessive residues. For these reasons, researchers in pest control have recently concentrated their efforts on the search for active natural products from plants as alternatives to conventional insecticides $[7,8]$.

pomegranates suffers from some pests such as Carob moth (Ectomeylois ceratoniae) I it is a polyphagous insect in larval stage, It is a considerable agricultural pest, recognized as the most economically damaging pest of the pomegranates in Kurdistan region of Iraq .This pest is distributed in Algeria, Tunisia, Turkey, Iran, Iraq ,USA. and many regions around the world, it also damages many other high value nut and fruit commodities such as almonds, pistachios, macadamias, stone and pome fruits, dates and macadamias [9]. (10). The appearance of black spots on the fruit is the first symptom of infection and the begging of rotting and rancidity process of the fruit. This pest hibernates in different larva instars in the remaining fruits on the trees, fruits under the trees, under the bark of the trees and on other hosts (11) .In early spring, the larvae gradually change into pupa and because pomegranates don't blossom at this time, the insects move to other hosts or die. Moths start appearing simultaneous with blossoming and fruiting and prolong until the end of June or beginning of July (12). Moths mate and lay on anthers, filaments and at times on the sepals, First phase larvae hatches out from the eggs and stays in the crown of pomegranate. This pest penetrates into the fruit at its late second or third larva instar (13), lowering the market value as a result of fungi attraction. This study investigates the efficacy of our locally plant extract with possible insecticidal activity for toxic efficacy against the larva. 


\section{Materials and Methods}

\section{Plant Material}

Fresh leaves of the plant: Mentha arvensis, and Nerium oleander were collected during 2010-2011 from Erbil city. The mentioned plants were washed with rinsed water, shade dried and well ground to a fine powder with an electric blender. The extracts of plants were prepared according to the methods described by Holopainen et al. $[14,15]$. One hundred gram of plant powder was dissolved separately in $300 \mathrm{~mL}$ of ethanol $70 \%$ (w/v) ratio at room temperature. The mixtures were stirred for 45 minutes in an ultrasonic bath at constant temperature of $25^{\circ} \mathrm{C}$, left to stand for 72 hours and shacked several times at certain intervals. All extracts were filtered through muslin cloth and then the solution was dried by vacuum rotary evaporator at $>40{ }^{\circ} \mathrm{C}[16]$.

\section{Mortality test}

Mortality test: To test the mortality rate or dose response of Ectomeylois ceratoniae to plant extracts, The residue was dissolved in distilled water at concentration 25,50 and $75 \mathrm{mg} / \mathrm{mL}$ [17]. Then $1 \mathrm{~mL}$ solution of each dose concentration was dropped on filter paper (watman no.40) in a Petri dish $(9 \mathrm{~cm}$ diameter) with the help of pipette and spread evenly throughout the Petri dish. The Petri dishes were then air dried for a few minutes. Ten insects were put into each Petri dish (three replicate/concentration). Control Petri dishes were treated with the distill water only. The mortality of beetles was recorded at 12, 24, 36, 48, 60 and 72 hours after treatment. The concentrations were calculated by measuring the dry weight of the crude extract applied into the Petri dish divided by the surface area of the respective Petri dishes [18]. 


\section{Statistical Analysis}

The mortality (\%) was corrected by Abbott's formula [19]. Probit analysis was used to estimate LC50 values by using SPSS software (V.20). Data analysis was made by using Factorial CRD. Least significant differences (LSD) at ( $P \geq$ 0.05) were applied to determine differences between treatments.

\section{Results and Discussion}

The corrected mortality with ethanol extract of Mentha arvensis on Ectomeylois ceratoniae was shown in Fig. (1). At 12 Hour the results indicates that the concentration $7.5 \%$ induce high mortality $83.3 \%$, while concentration $2.5 \%$ and $5 \%$ cause mortality $73.3 \%$ and $66.7 \%$ respectively. There is no significant differences were shown between all treatments at 12 hour. At 24 hour concentration of $5 \%$ and $7.5 \%$ cause $16.7 \%$ mortality, while $2.5 \%$ induce $10 \%$. At 36 hour the mortality was $3.3 \%$ and $13.3 \%$ for concentrations $2.5 \%$ and $5 \%$ respectively. A 60 hour the mortality was $13.3 \%$ and $6.7 \%$ for concentrations $2.5 \%$ and $5 \%$ respectively (figure 1) and (table A and B)

The Nerium oleander extract had high toxicity at 12 hour after treatment for used concentrations which causes $33.33 \%$ and $43.33 \%$ and $63.33 \%$ for concentrations $2.5 \%, 5 \%$ and $7.5 \%$ respectively, statistically there is significant differences shown between all concentrations at 12 hour. At 24 hour the concentration $2.5 \%$ cause $20 \%$ mortality followed by $5 \%$ and $7.5 \%$ which causes $10 \%$ and $13 \%$ statistically there is no significant differences shown between all concentrations at 24 hour. Mortality at 36 hour was $10 \%, 16 \%$ and $13 \%$ for used concentrations $2.5 \%, 5 \%$ and $7.5 \%$. At 48 hour concentration $\% 2.5,5 \%$ and $7.5 \%$ induce $6.7 \%, 3.3 \%$ and $10 \%$, while at 60 hour and 72 hour after treatment concentration 5\% and $2.5 \%$ induce $26.7 \%$ and $30 \%$ mortality, statistically there is no significant differences shown between all concentrations at 36 hour and 48 hour. But there is a significant 
difference between concentrations $2.5 \%$ and $5 \%$ for both 60 our and 72 hour (figure 2 and (table A and B)

Mentha

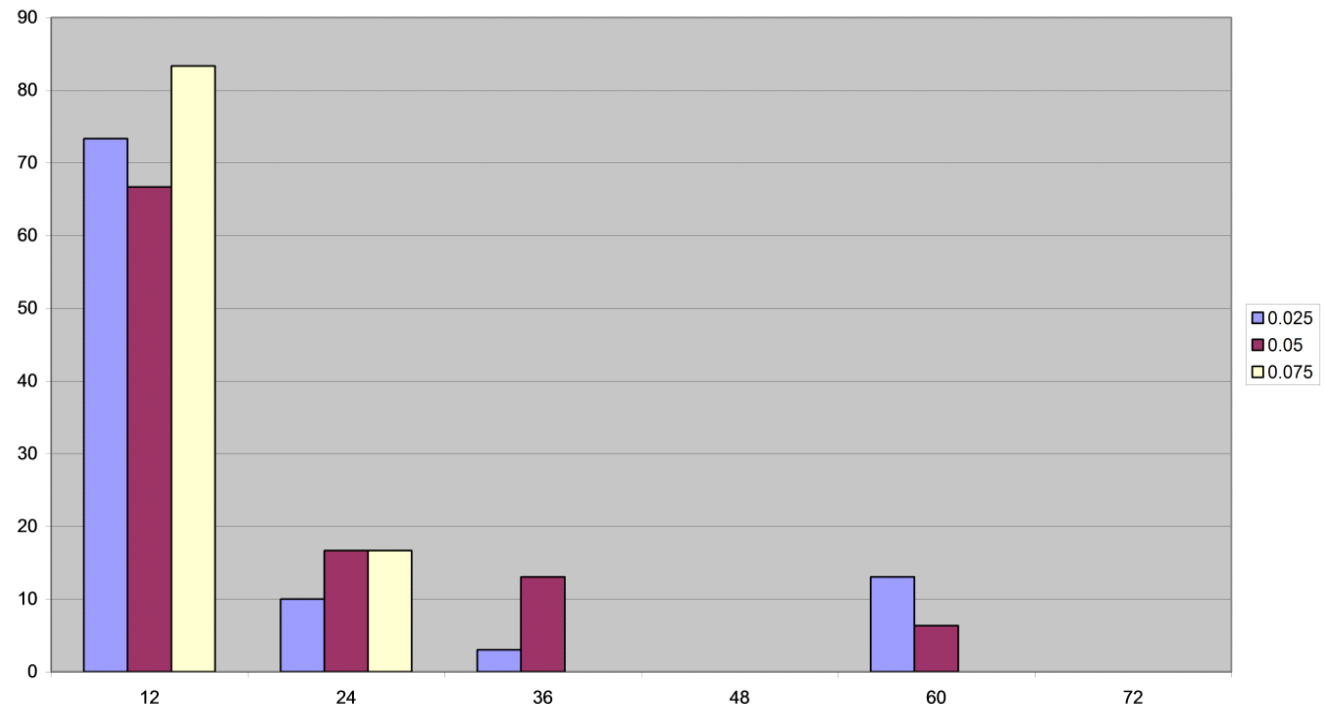

Figure 1: Effect of different concentrations of Mentha arvensis on mortality of Ectomeylois ceratoniae larvae during exposure period

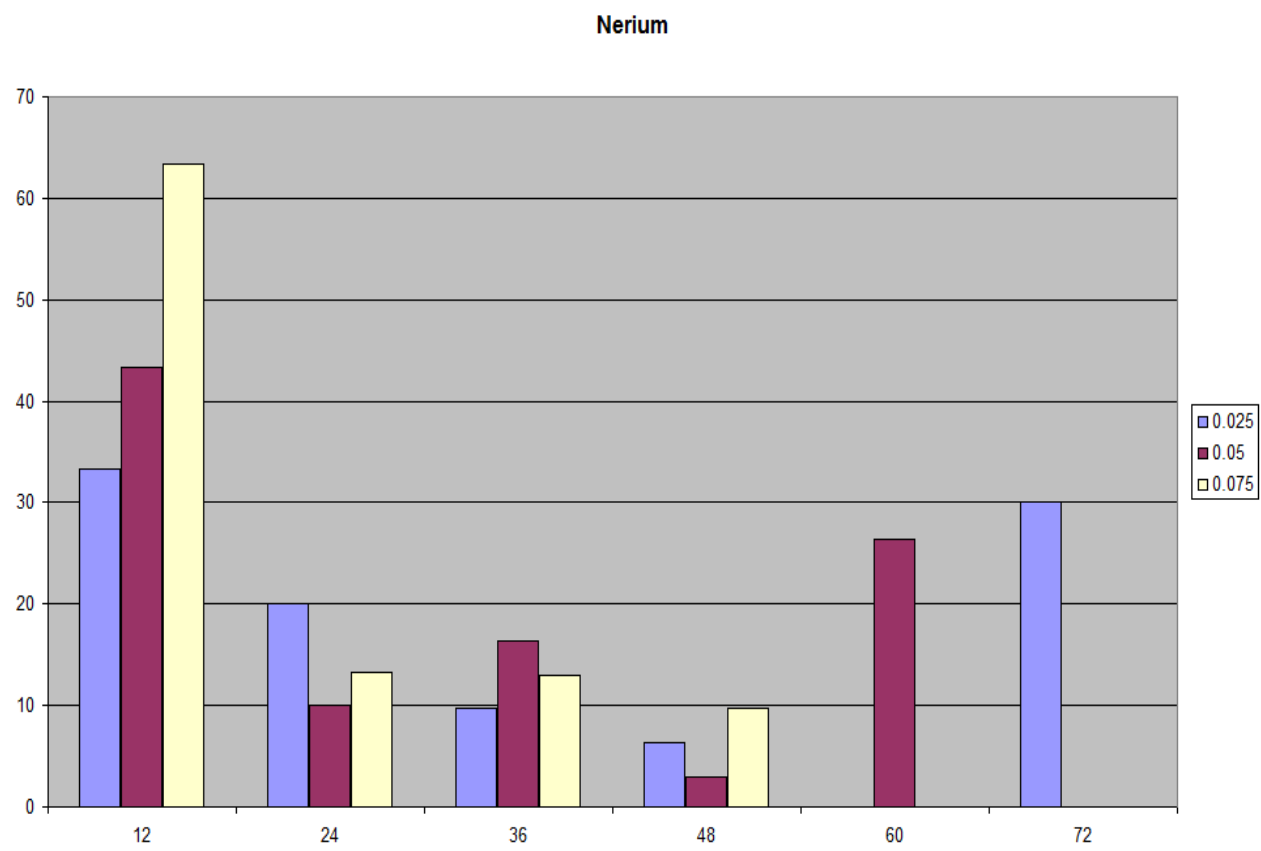

Figure 2: Effect of different concentrations of Nerium oleandr on mortality of Ectomeylois ceratoniae larvae during exposure period 


\begin{tabular}{|c|c|c|c|c|c|c|c|c|c|c|c|c|c|}
\hline \multirow[t]{2}{*}{ Plant } & \multirow{2}{*}{$\frac{\text { Con. }}{\text { Time }}$} & \multicolumn{12}{|c|}{ Mean } \\
\hline & & \multicolumn{2}{|l|}{12} & \multicolumn{2}{|c|}{24} & \multicolumn{2}{|l|}{36} & \multicolumn{2}{|l|}{48} & \multicolumn{2}{|l|}{60} & \multicolumn{2}{|l|}{72} \\
\hline \multirow{4}{*}{$\begin{array}{l}\text { Mentha } \\
\text { arvensis }\end{array}$} & $2.5 \%$ & 73.3 & $\mathrm{~b}$ & 10 & $\mathrm{Ab}$ & 3.3 & $\mathrm{a}$ & 0.00 & $\mathrm{a}$ & 13.3 & $\mathrm{a}$ & 3.3 & $\mathrm{~A}$ \\
\hline & $5 \%$ & 66.7 & $\mathrm{~b}$ & 16.7 & B & 13.3 & $\mathrm{a}$ & 0.00 & $\mathrm{a}$ & 6.7 & $\mathrm{a}$ & 0.00 & A \\
\hline & $7.5 \%$ & 83.3 & $\mathrm{~b}$ & 16.7 & B & 0.00 & $\mathrm{a}$ & 0.00 & $\mathrm{a}$ & 0.00 & $\mathrm{a}$ & 0.00 & $\mathrm{~A}$ \\
\hline & Control & 0.00 & $\mathrm{a}$ & 0.00 & $\mathrm{~A}$ & 0.33 & $\mathrm{a}$ & 0.33 & $\mathrm{a}$ & 0.33 & $\mathrm{a}$ & 0.00 & $\mathrm{~A}$ \\
\hline \multirow{4}{*}{$\begin{array}{l}\text { Nerium } \\
\text { oleander }\end{array}$} & $2.5 \%$ & 33.3 & $\mathrm{~b}$ & 20.00 & B & 10.00 & $\mathrm{a}$ & 6.7 & $\mathrm{a}$ & 0.00 & $\mathrm{a}$ & 3.00 & $\mathrm{~B}$ \\
\hline & $5 \%$ & 43.3 & $\mathrm{c}$ & 10.00 & $\mathrm{Ab}$ & 16.7 & $\mathrm{a}$ & 3.3 & $\mathrm{a}$ & 26.7 & $\mathrm{~b}$ & 0.00 & A \\
\hline & $7.5 \%$ & 63.3 & $\mathrm{~d}$ & 13.3 & $\mathrm{Ab}$ & 13.3 & $\mathrm{a}$ & 10.00 & $\mathrm{a}$ & 0.00 & $\mathrm{a}$ & 0.00 & $\mathrm{~A}$ \\
\hline & Control & 0.00 & $\mathrm{a}$ & 0.00 & $\mathrm{~A}$ & 0.33 & $\mathrm{a}$ & 0.33 & $\mathrm{a}$ & 0.33 & $\mathrm{a}$ & 0.00 & $\mathrm{~A}$ \\
\hline
\end{tabular}

Table A: Effect of Mentha arvensis, and Nerium oleander on mortality of Ectomeylois ceratoniae larvae during exposure period

\begin{tabular}{|c|c|c|c|c|c|c|c|}
\hline \multirow[t]{2}{*}{ Plants } & \multirow{2}{*}{$\begin{array}{c}\text { Doses } \\
(\mathrm{mg} / \mathrm{ml})\end{array}$} & \multicolumn{6}{|c|}{ Probit Mortality } \\
\hline & & 12 & 24 & 36 & 48 & 60 & 72 \\
\hline \multirow{4}{*}{$\begin{array}{l}\text { Mentha } \\
\text { arvensis }\end{array}$} & 25 & 0 & 0 & 0 & 0 & 0 & 12 \\
\hline & 50 & 6.17 & 29.48 & 13.49 & 1.82 & 66.67 & 0 \\
\hline & 75 & 0 & 0 & 0 & 0 & 0 & 0 \\
\hline & $\mathrm{LD}^{50}$ & 1.75 & 1.12 & 1.29 & 6.67 & 1.05 & 2.55 \\
\hline \multirow{4}{*}{$\begin{array}{l}\text { Nerium } \\
\text { oleander }\end{array}$} & 25 & 33.33 & 20 & 9.7 & 6.35 & 0 & 30 \\
\hline & 50 & 43.3 & 10 & 16.39 & 3.01 & 26.42 & 0 \\
\hline & 75 & 63.33 & 13.33 & 13.04 & 9.7 & 0 & 0 \\
\hline & $\mathrm{LD}^{50}$ & 0.13 & 1.52 & 0.76 & 0.41 & 1.14 & 2.44 \\
\hline
\end{tabular}

Table B: Effect of Mentha arvensis, and Nerium oleander on mortality of Ectomeylois ceratoniae larvae during exposure period

\section{CONCLUSION}

The findings of the present investigations indicate that botanical derivatives might be useful as insect control agents for commercial use. The results of the present study indicated that the time $12 \mathrm{~h}$ showed higher insecticidal effect with the Mentha arvensis and Nerium oleander on mortality of Ectomeylois ceratoniae larvae during exposure period, Strong toxicity effect was observed at concentration $7.5 \%$. A study to improve the effectiveness of botanical derivatives as insecticides 
will benefit the agricultural sectors of developing countries, as these substance are not only of low cost, but also have less environmental impact in terms of insecticidal hazard.

\section{References}

1. Lamiri A, Lhaloui S, Benjilali B, Berrada M. Insecticidal effects of essential oils against hessian fly, Mayetiola destructor (Say). Field Crop Res. 2001;71:915.

2. Tapondjou AL, Adler C, Fontem DA, Bouda H, Reichmuth C. Bioactivities of cymol and essential oils of Cupressus sempervirens and Eucalyptus saligna against Sitophilus zeamais Motschulsky and Tribolium confusum du Val. J Stored Prod Res. 2005;41:91-102.

3. Bughio FM, Wilkins RM. Influence of Malathion resistance status on survival and growth of Tribolium castaneum (Coleoptera: Tenebrionidae), when fed on four from insect-resistant and susceptible grain rice cultivars. J Stored Prod Res. 2004;40:65-75.

4. Athie I, Mills KA. Resistance to phosphine in stored-grain insect pests in Brazil. Braz. J. Food Technol. 2005;8(2):143-47.

5. Chowdhury H, Kar CS, Sarkar SK, Tripathi MK. Feeding inhibitory effect of some plant extracts on jute hairy caterpillar (Spilosoma obliqua). Indian J Agri Sci. 2012;82(1):59-62.

6. Prakash A, Rao J. Botanical pesticides in agriculture, CRC Press, Baton Rouge, Florida, USA; 1997.

7. Isman MB. Plant essential oils for pest and disease management. Crop Protect. 2000;19:603-08.

8. Isman MB. Perspective botanical insecticides:For richer, for poorer. Pest Manag Sci.2008;64:8-11. 
9. Saad, A. H and Amin, A. H., Economic insects in northern Iraq, University of Mosul, Mosul, 1983, 307-310 pp. (In Arabic).

10. Warner RL, Barnes MM, Laird EF. Chemical control of a carob moth, Ectomyelois ceratoniae (Lepidoptera: Pyralidae), and various nitidulid beetles (Coleoptera) on 'Deglet Noor' dates in California. Journal of Economic Entomology.1990; 83(6): 2357-2361.

11. Ahmadian, H. Final report from efficiency investigation Trichogramma spp. against Ectomyelois ceratoniae. Agriculture Researches Center of Yazd (plant diseases and pests part), 1993, $136 \mathrm{pp}$.

12. Shakeri, M. \& Sadat Akhavi, Y. Pest and desease of pomegranate.Tasbih publication. Agriculture Researches Center of Yazd, 2003,126 pp.

13. Farzaneh, A. Ectomyelois ceratoniae in Iran. Papers of First symposium of pomegranate problems investigation in Iran. University Jehad of Agriculture College and Natural Resource of Tehran, 1987, (1): 17-19.

14. M. Holopainen, L. Jahodar, Kauppien I. Seppanen-Laokso, Antimicrobial activity of some Finnish ericaceous plants, Acta Pharmaceutica Fennica,1988, (97); 197-202.

15. R. Valsaraj, P. Pushpangadan, U.W. Smitt, A. Adsersen, U. Nyman, Antimicrobial screening of selected medicinal plants from India, Journal of Ethnopharmacology, 1997, (58); 75-83.

14. B.M. Rejesus, Botanical insecticides against the diamond back moth, Los Banos, Philippines: Entomology, HANA, 2009, 241-254.

16. B.R. Kundu, R. Begum. M.M. Ara, Z.I. Sarker, Effect of Bishkatali, Polygonum hydropiper L. plant extracts against the red flour beetle, Tribolium castaneum Herbst, J. Zool. Rajshahi Univ., 2007, (26);93-97.

17. W.S. Abbott, A method for computing the effectiveness of an insecticide, J. Econ. Entomol., 1925, (18);265-267.

19. D.J. Finny, Probit Analysis, Cambridge University Press London, 1971, p. 333 